\title{
CARBON MONOXIDE AND CARBON DIOXIDE LEVEL DISTRIBUTION OF ROJHELAT CAFE IN DUHOK CITY
}

\author{
Diyar Ahmad Sayib Sadiqa, *, and Wasfiya Ali muneer ${ }^{\mathrm{a}}$ \\ a'Dept. of Physics, College of Science, University of Zakho, Kurdistan region, Iraq - (diyar.sadiq@uoz.edu.krd)
}

Received: Dec. 2017 / Accepted: Apr., 2018 / Published: Jun., 2018

https://doi.org/10.25271/2018.6.2.453

\begin{abstract}
:
There are a few data of toxic concentrations and their distribution of cigarrete and Shisha smoking in Café. Therefore, the aim of this study is to know the concentration and the distribution of both CO and CO2 gases in Rojhelat Café in Duhok city. Both gases have been measured in different positions of Café before opening and until closing the place. Furthermore, the distributions of gases at different places and different elevation have been measured. The results showed that the effect of shisha on producing gases is more than cigarrete. We found that the toxic gases in Café were too high. This study will help the Café manufacture how to design the building such Café for air conveyor and condition.
\end{abstract}

Keywords: Carbon monoxide, Carbon dioxide, Shisha cafes.

\section{INTRODUCTION}

Daily peoples are going to spend many hours in cafes mainly for smoking proposes (mostly shisha) in middle east region. This is an old tradition that goes back (Organization W. H., Tobacco use in shisha: studies on waterpipe smoking in Egyp, 2006) which is a most public health problem. No single disease is expected to make such a giant claim on health as smoking risk factor (Organization W. H., 1999). Smoking tobacco preparations in a shisha or water pipe is popular in many places of the world including USA (Peyton, Abu, Delia, Christopher, \& Margaret, 2011), Asia (Akhter, Warraich, Rizvi, Idrees, \& Zaina, 2014), Middle East (Kiter, Ucan, Ceylan, and, \& O., 2000), North Africa (Israel, El-Setouhy, Gadalla, Ali, Nabiel, \& K, 2003) and also Iraq-Kurdistan Region. Smoking motivation and revert, as well as levels of consumption, may be strongly affected by social environments (Chan, et al., 2014). A typical session at a shisha bar involves smoking for 45-60 minutes (Organization W. H., Waterpipe tobacco smoking: health effects, research needs and recommended actions for regulators, 2015), often with a group of friends. Waterpipes, waterpipe tobacco, and accessories are sold in smoke shops and over the Internet. Many people who smoke waterpipe tobacco preparations believe that it is not addictive, and less harmful than cigarette smoking. Sharing the same waterpipe is also a well-recognized, widespread practice, especially among young people (Organization W. H., Waterpipe tobacco smoking: health effects, research needs and recommended actions for regulators, 2015).

There are many studies examined the effect of smoking on the human health (Akhter, Warraich, Rizvi, Idrees, \& Zaina, 2014; Neslihan \& Nurten, 2010; Singh, M, Saini, Mittal, \& Singh, 2011). For example, the increase in end tidal carbon monoxide (eCO) levels in exhaled breath of passive smokers and healthy smokers after cigarette and shisha smoking has been analyzed (Akhter, Warraich, Rizvi, Idrees, \& Zaina, 2014). The study shows that the Active and passive exposure to Shisha smoking is a cause of increased eCO in smokers and nonsmokers. This gives the evidence that the effect of the Shisha smoking is larger than cigarrete. Furthermore, the effect of both shisha and cigarette smoking toxic on semen parameters and hormones levels of cigarette smokers and non-smokers has been studied (Neslihan \& Nurten, 2010). The researcher showed that shisha intoxication is more significant than cigarette by lowering semen volume, sperm count and the percentage of healthy sperms (Irene, Nashwa, Kamal, \& Abdulla, 2011).

The significant effects of smoking and specifically Shisha on the human health attract researchers to study quantitatively the chemistry and physical phenomena of both cigarrete and Shisha (Israel, El-Setouhy, Gadalla, Ali, Nabiel, \& K, 2003; Kiter, Ucan, Ceylan, and, \& O., 2000; Dahe, et al., 2010; Akhter, Warraich, Rizvi, Idrees, \& Zaina, 2014; Lim, Lim, \& Seow, 2009). For example, the study of absorption of nicotine, carbon monoxide, and carcinogens from one waterpipe smoking found a significant increase in plasma nicotine concentrations, comparable to cigarette smoking; however, an increases in carbon monoxide levels that are much higher than is typically observed from cigarette smoking (Peyton, Abu, Delia, Christopher, \& Margaret, 2011). The study of fraction and size of carbon monoxide (CO) in Shisha and cigarette smoking show that the concentration is high for small sizes of Shisha comparing to cigarette (Sajid, Akhter, \& Malik, 1993). Due to the rapid increases in Shisha use in Café in Iraq Kurdistan-Region, more data are needed about the distribution of $\mathrm{CO}$ and $\mathrm{CO}_{2}$ inside the Café. There are many studies of cigarette and Shisha smoking in different geographical place outside (Chan, et al., 2014; Pearson \& Thomson, 2014) and inside bars and cafés (Organization W. H., Tobacco use in shisha: studies on waterpipe smoking in Egyp, 2006; Israel, ElSetouhy, Gadalla, Ali, Nabiel, \& K, 2003; Barnett, Curbow, Soule, \& Thombs, 2011) have been presented. Previous studies about cigarette and Shisha smoking show that exposure to Shisha smoking in bar and Café cause significant increase in exhaled Carbon mono oxide level (Akhter, Warraich, Rizvi, Idrees, \& Zaina, 2014). Another study shows that CO level are higher for patrons of Shisha smoking in Café for both current and non-cigarette smokers (Sajid, Akhter, \& Malik, 1993). Café place has been used to study assessed beliefs about the harmfulness of smoking Shisha (Aljarrah, Ababneh, \& AlDelaimy, 2009). They showed that lack of acknowledge about the harmfulness of smoking Shisha among users depending on demographic background. However, from our

\footnotetext{
* Corresponding author
} 
acknowledgement there is no study about the $\mathrm{CO}$ and $\mathrm{CO} 2$ distribution and concentrations in Café. Here we study and analyses how both gases distribute inside Café. We measure both gases in smoker table and in a place where no smoker is near. At the same places we measure the distribution of both gases along the height of Café.

\section{MATERIAL AND METHODS}

The study site was a Café called Rojhelat in Duhok City, in Iraq Kurdistan-region. The dimension of the building is $10 \times 10 \times 4 \mathrm{~m}$. The concentrations of exposure to $\mathrm{CO}(\mathrm{ppm})$ and $\mathrm{CO}_{2}(\mathrm{Vol} \%)$ was determined by measuring both gases in air. The concentration of exposures were measured by recording and monitoring both gases simultaneously using Dräger X-am 2500 calibrated detector at baseline, from 04:00 PM to 03:00 AM and for each 10 minute, namely when the Café was opened until become free of smokers. In order to obtain better information about the exposure level of both gases, the measurements were performed by taking 10 minute average value for each individual value. This will prevent any measurement fluctuation that may effect on the real information of this study. We have chooses two different places to obtain better

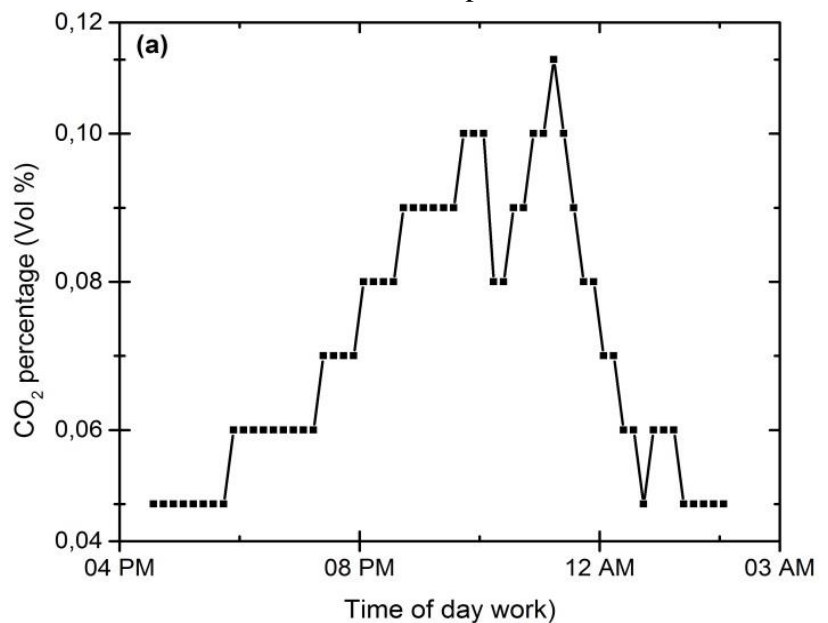

information of both gases distribution. First place was far away from smokers table (case 1) while the second one was at a smokers stable (case 2). The detector was placed 1 meter above the floor of Café. It has to be mentioned that around 8 smokers and 6 Shisha smokers sitting at a subject table and around 16 smokers were inside the Café. At the same places, the measurements have been done along the height of the Café. This would give us better information about the distribution of both gases inside Café. The mean numbers of Shisha that have been used for two cases, the case where the detector placed far from the smoker and the case where the detector placed at smoker table were 10 Shisha.

\section{RESULTS AND DISCUSSIONS}

For the first case, one can see clearly from figure 1, that for $\mathrm{CO}_{2}$ (a) and $\mathrm{CO}$ (b) the concentrations raised at the beginning of the day work and reached its maximum at time $23 \mathrm{AM}$ then it decreased deeply during the end of the day work. The concentration of $\mathrm{CO}_{2}$ reaches $0.11 \%$ while for $\mathrm{CO}$ it reaches $26 \mathrm{ppm}$. It should be mentioned that both measurements have been recorded simultaneously.

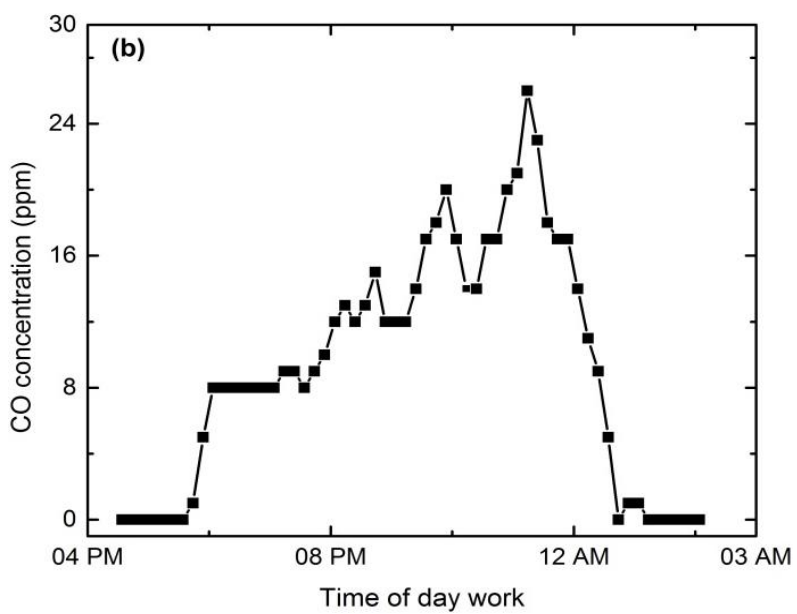

Figure 1. the concentration of (a) $\mathrm{CO}_{2}$ in volume $\%(\mathrm{Vol} \%$ ) and (b) $\mathrm{CO}$ parts per million (ppm) measurements as a function of time of day work for case 1 .

For the second case, the case where the detector was placed at smoker tables, the relations show pronounced increase with respect with the first case as shown in figure 2. For this case, the numbers of Shisha were also 10 Shisha. The increase for the case 2 (at the smoker table) is about $11 \%$ larger than for the case 1. This value of course will be different for different number of Shisha. One can see a well correlation between $\mathrm{CO}$

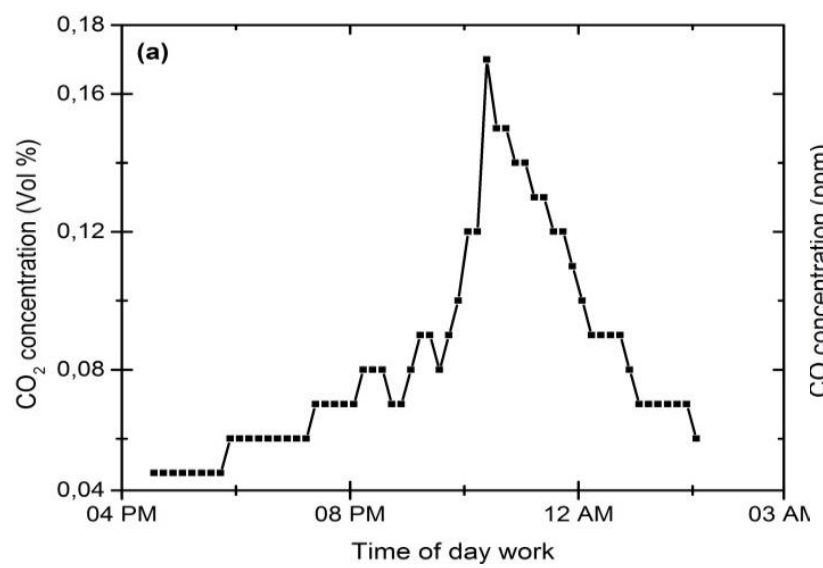

and $\mathrm{CO}_{2}$ measurement for both cases. This means that the main sources of both gases are Shisha. Consequently, this means that Shisha is more used at least in this Café but we thing that this will be for the majority Cafés in Kurdistan-Region. This means that Shisha is more risk factor smoking than the regular cigarette. This means that the Shisha is more toxic as compared to cigarette smoking.

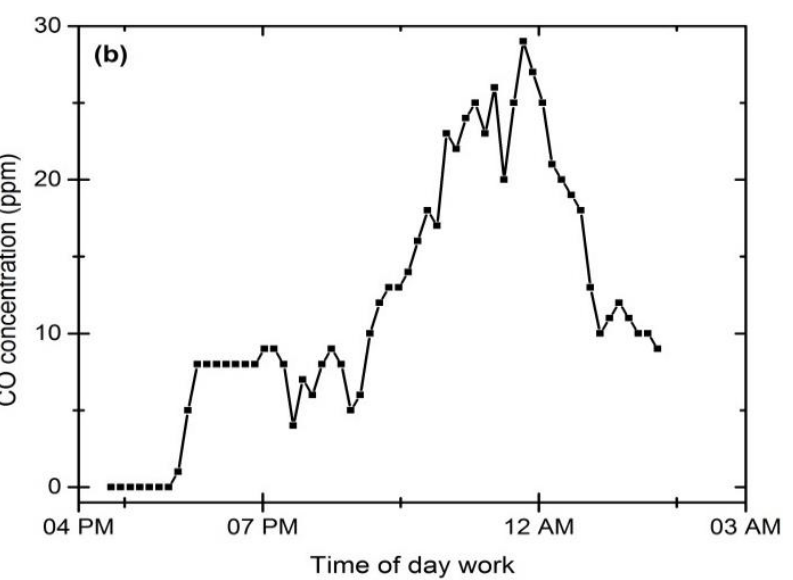

Figure 2. the concentration of (a) $\mathrm{CO}_{2}$ in volume $\%(\mathrm{Vol} \%$ ) and (b) $\mathrm{CO}$ in parts per million (ppm) measurements as a function of time of day work for case 2 . 
In order to obtain better information about the distribution of both gases, the concentrations of both gases have been recorded at 7 elevations above ground surface with the same parameter, namely 15 -minute average of the recorded value for each 50 $\mathrm{cm}$ height as shown in figure 3 and figure 4 . From figure 3 , it is clearly visible that the level at which the $\mathrm{CO}_{2}$ is maintained at $150 \mathrm{~cm}$ height in a place far from the smoker table (figure 3

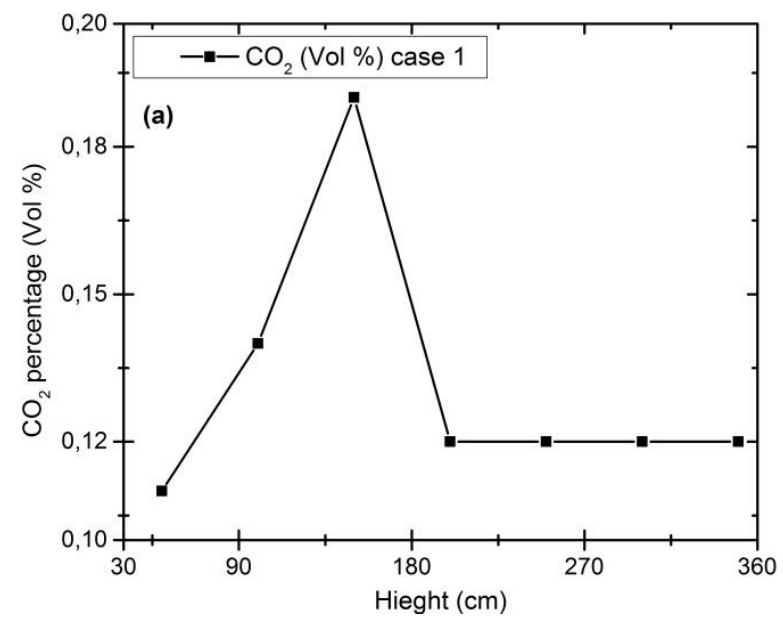

(a)). However, for case 2 the maintained level was about 200 $\mathrm{cm}$ height (figure 3 (b)). This means that for case 1 , the toxic $\mathrm{CO}_{2}$ is closer to the level where the peoples are sitting. For case 2 this is a little bit different and the level where the peoples are setting was higher, but the concentration of $\mathrm{CO}_{2}$ is larger as compared to the case 1 .

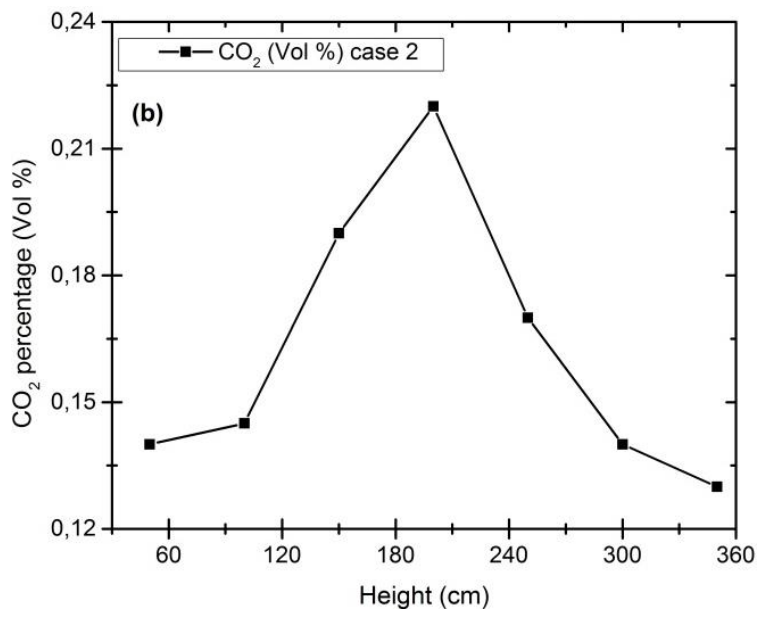

Figure3. (a) $\mathrm{CO}_{2}\left(\mathrm{Vol} \%\right.$ ) for case 1 (b) $\mathrm{CO}_{2}(\mathrm{Vol} \%)$ for case 2 as a function of altitude.

The same measurements have been done for $\mathrm{CO}$ as shown in figure 4. Figure 4 (a) for case 1 shows that the level of $\mathrm{CO}$ of $26 \mathrm{ppm}$ keeps constant at around $200 \mathrm{~cm}$. For case 2 the measurement shows different relation between elevation above the ground surface and the concentration of $\mathrm{CO}$ as shown in figure 4 (b). As one can see clearly that the concentration of $\mathrm{CO}$ is larger than the case 1 (36 ppm) and the concentration does not maintained at any specified height. The measurements show that the concentration of $\mathrm{CO}$ in general is high and can be
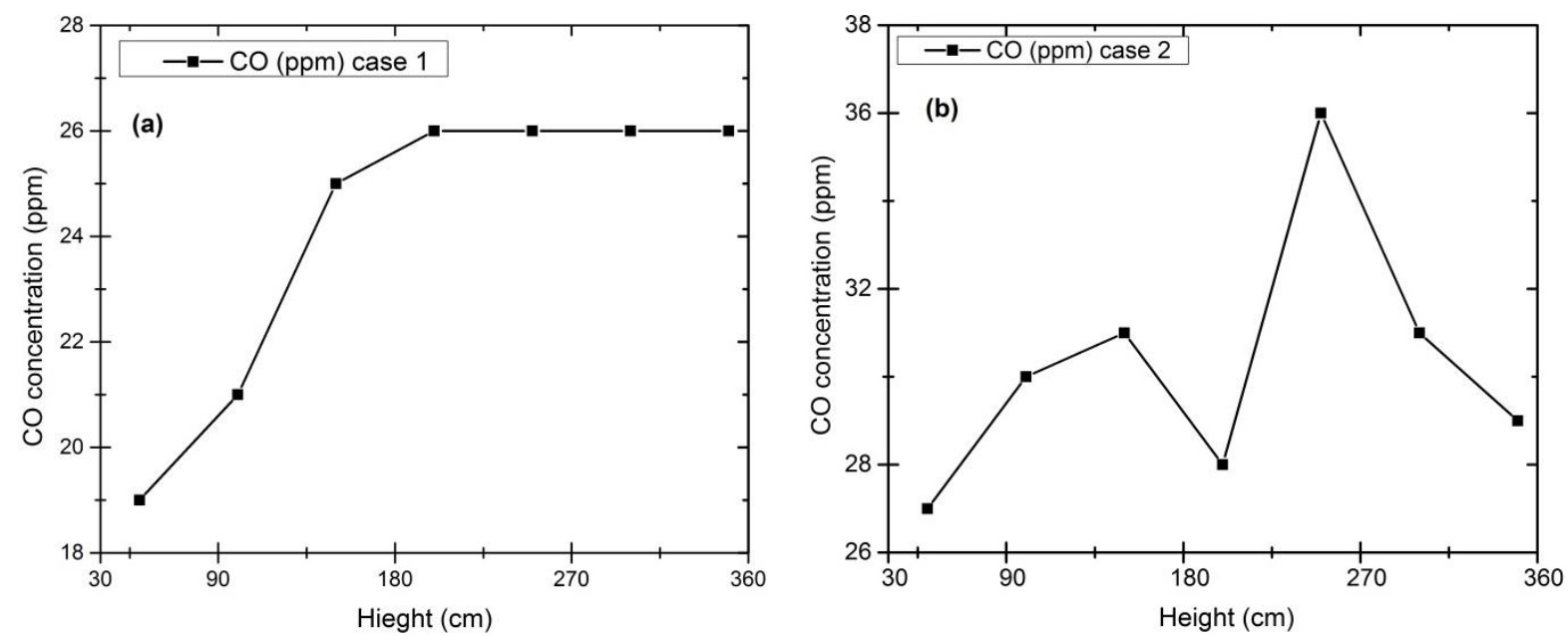

Figure 4. (a) $\mathrm{CO}(\mathrm{Vol} \%$ ) for case 1 (b) $\mathrm{CO}(\mathrm{Vol} \%$ ) for case 2 as a function of altitude.

\section{CONCLUSION}

Our study shows that the $\mathrm{CO}_{2}$ and $\mathrm{CO}$ level and concentrations are the main sources of the both toxic gases and are higher than regular cigarette smoking. Thus, Shisha is higher toxic and risk factor than cigarette smoking. Furthermore, our study presents the distribution of $\mathrm{CO}_{2}$ and $\mathrm{CO}$ is different for different places and different elevation. Also, our study shows that the maximum concentration of $\mathrm{CO}$ was $36 \mathrm{ppm}$ for about 10 shisha smoking or $3.6 \mathrm{ppm} / \mathrm{one}$ Shisha. The results of this study would help also the Café manufactures to provide more conveyers at the appropriate place. Knowing the distribution and more increased depending on the number of Shisha smokers. It is well known that $\mathrm{CO}_{2}$ is slightly heavier than air while $\mathrm{CO}$ is slightly lighter than air. Thus, $\mathrm{CO}$ gas can be found at higher level of elevation while $\mathrm{CO}_{2}$ in lower comparing with $\mathrm{CO}$. This is clearly visible by comparing figure 3 (a) with figure 4 (a). Moreover, comparing with $\mathrm{CO}_{2}, \mathrm{CO}$ gas is significantly affected by any random movement as a consequence of slighter light weight. This can be seen clearly in figure 4 (a). concentration fraction and concentrations of both gases will help the Café manufacture where to put their air filter and flow box. Also, it would help to promote develop health initiatives cigarrete and specially Shisha user according to their belief about the harmfulness of smoke and specifically Shisha smoking in Café.

\section{REFERENCES}

Akhter, S., Warraich, U. A., Rizvi, N., Idrees, N., \& Zaina, a. F. (2014). Comparison of end tidal carbon monoxide (eCO) levels in 
shisha (water pipe) and cigarette smokers. Tobacco Induced Diseases, 10.

Aljarrah, K., Ababneh, Z. Q., \& Al-Delaimy, a. W. (2009). Perceptions of hookah smoking harmfulness: predictors and characteristics among current hookah users. Tobacco Induced Diseases, 5(16)

Barnett, T. E., Curbow, B., Soule, E. K., \& Thombs, D. L. (2011). Carbon monoxide levels among patrons of hookah cafes. American journal of preventive medicine, 40(3), 324-8.

Chan, J., Burnett, T., Baillie, R., Blomfield, S., Dickson, P. C., Fleishl, W., et al. (2014). Smoking in outdoor areas of bars and cafe's: Large differences between midday and evening prevalences. Drugs: education, prevention and policy, 21(6), 484-488.

Dahe, N., Saleh, R., Jaroudi, E., Sheheitli, H., Badr, T., Sepetdjian, E., et al. (2010). Comparison of carcinogen, carbon monoxide, and ultrafine particle emissions from narghile waterpipe and cigarette smoking: Sidestream smoke measurements and assessment of second-hand smoke emission factors. Atmospheric Environment, 44, 8-14.

Irene, A., Nashwa, N. F., Kamal, M., \& Abdulla, a. A. (2011). Reproductive Toxicity of Tobacco Shisha Smoking on Semen Parameters and Hormones Levels among Adult Egyptian Men. Research Journal of Environmental Toxicology, 5(5), 282-292.

Israel, E., El-Setouhy, M., Gadalla, S., Ali, A. E., Nabiel, M., \& K, M. M. (2003). WATER PIPE (SISHA) SMOKING IN CAFÉS IN EGYPT. Journal of the Egyptian Society of Parasitology, 3, 1073 - 1085.

Kiter, G., Ucan, E., Ceylan, E., and, K., \& O. (2000). Water-pipe smoking and pulmonary functions. Respir. Med, 94(9), 891894.
Lim, B. L., Lim, G. H., \& Seow, E. (2009). Case of carbon monoxide poisoning after smoking shisha. International Journal of Emergency Medicine, 2, 121-122.

Neslihan, D. g., \& Nurten, S. (2010). Effects of Work Place Carbon Monoxide Exposure on Blood Viscosity. Archives of Environmental \& Occupational Health, 65(1), 49-53.

Organization, W. H. (1999). Tobacco-Health facts. Organization, World Health, 221.

Organization, W. H. (2006). Tobacco use in shisha: studies on waterpipe smoking in Egyp. WHO Regional Office for the Eastern Mediterrancan.

Organization, W. H. (2015). Waterpipe tobacco smoking: health effects, research needs and recommended actions for regulators. Switzerland: World Health Organization.

Pearson, A. L., \& Thomson, D. N. (2014). Measuring visual exposure to smoking behaviours: a viewshed analysis of smoking at outdoor bars and cafés across a capital city's downtown area. BMC Public Health, 300(14), 1471-2458.

Peyton, J., Abu, R. A., Delia, D., Christopher, H., \& Margaret. (2011). Nicotine, Carbon Monoxide, and Carcinogen Exposure a Single Use of waterpipe. Cancer Epidemiol Biomarkers Prevention, 20(11), 2345-2353.

Sajid, K. M., Akhter, M., \& Malik, G. Q. (1993). Carbon Monoxide Fractions in Cigarette and Hookah (Hubble Bubble) Smoke. Journal of Pakistan Medical Association, 43(9), 179-182.

Singh, S., M, S., Saini, A., Mittal, V., \& Singh, U. V. (2011). Breath Carbon Monoxide Levels in Different Forms of Smoking. Indian Journal of Chest Disease and Allied Science, 5(1), 25-28. 